\title{
Educational egaming: the future for geoscience virtual learners?
}

Jamie K. Pringle

School of Physical Sciences \& Geography, William Smith Building, Keele, University, Keele, Staffs, ST5 5BG, UK.

Email: j.k.pringle@keele.ac.uk

\begin{abstract}
Current student learners will mostly comprise so-called Generation $Y$ who have grown up with personal computer and egaming technologies. They are used to a variety of digital learning environments and educational egaming may therefore provide effective complementary learning to more traditional learning and teaching methods. This paper briefly reviews current geoscience digital educational methods and details three case studies of online educational geoscience egames. These are shown to provide a consistent experience, 24/7 accessibility and effective learning. Links to use these resources are given.
\end{abstract}

\section{Introduction}

The structured nature of traditional lectures and associated laboratory practicals still dominate in today's science teaching and learning disciplines. Whilst these are appropriate learning and teaching methods for some students, there are a whole variety of other ways that practitioners have found that are used to learn, for example, mutual group learning, interactive learning and problem-based learning to list but three. Some of these can be usefully applied in practical sessions. Outdoor fieldwork-based geoscience learning has well documented 
and obvious benefits of 'learning through doing', potentially greater student engagement with the topics, exploration learning as outcrops are investigated and analysed, etc., and it is not the intention of this paper to suggest egaming as a replacement for fieldwork. However, the opportunities to actually undertake geoscience fieldwork for learners during their studies can be relatively few, due to, for example, formal timetabling constraints, fieldwork logistics and the expense incurred for both learners and providers. Some of the best field areas are relatively inaccessible, especially for those who may not be physically able, the trip may additionally suffer with inclement weather, etc., which can make them not as effective as planned, even taking the same field trip over different years.

The current college and undergraduate University student cohort have changed from the so-called Generation $X$ to now mostly comprise Generation $Y$ (generally defined as having 1982-2001 birth years). Generation $Y$ learners have grown up with computers and computer gaming, are fully digitally conversant and able and indeed wanting to be connected to the internet 24/7. Surveys on 61 current Geoscience students at Keele University have found three quarters play computer games daily or weekly and half have already used online resources for learning (e.g. BBC ${ }^{\mathrm{TM}}$ Bitesize online examination revision tools). Researchers taking Generation $Y$ as a whole, they are found to be used to instant messaging and therefore tend to want instant results from learning, are bored by routine and additionally need active engagement in tasks to remain focused on learning. That said, however, they are highly competent users of information technologies and have been shown to integrate a variety of tasks simultaneously, responding particularly well to goal-orientated tasks. As an example, a particularly popular multi-player fantasy world online game (World of Warcraft ${ }^{\mathrm{TM}}$ ) involves navigating a personal virtual avatar of the user around a virtual world, various online and interactive tasks needing to be completed and additionally the ability to verbally communicate with virtual avatars of other users, all of which is undertaken simultaneously, which obviously involves a variety of learning methods! 


\section{Virtual educational learning}

On-line learning environments are all but most compulsory for teaching modules at college and University, the best resources being a rich mixture of taught and online materials. These materials are interspersed with video and digital animations; for example, explaining the 3D relationships of structuring folding of rocks or the evolution of sedimentary basins and their sediment types and their distributions in three dimensions over time. Recorded video podcasts of fieldtrips have also been shown to be very useful for learners for pre-trip familiarization and visualization, or indeed for those unable to make the trip yet still gaining appropriate learning outcomes. Digital reconstructions of rock outcrops and/or real-world environments are also increasingly popular for a range of teaching and research applications (Figure 1). In other applied science areas, for example, in applied engineering, students can, for example, virtually work through how to assemble turbine generator parts before physically undertaking the task, which has obvious benefits of pre-assembly familiarising with the parts, making virtual mistakes and solving them and foreseeing problems before they physically occur.

Taking away real-world reality has also been shown to be useful for educational purposes, for example, immersive virtual learning environments have been around for some time, the online SecondLife ${ }^{\mathrm{TM}}$ multi-player online environments have been used by both science researchers and teachers, and has even been used as virtual academic conference venues. However, generally, these have had mixed success for effective learning for a variety of reasons, including users having had variable previous experiences and thus some novice users struggle more than others, a dependence on learners fully engaging with the scenario to be successful, distractions of the virtual environment itself and navigating the user's virtual avatar around, and lastly, difficulty actually finding the named virtual conference venue within the virtual world, to name but four. 


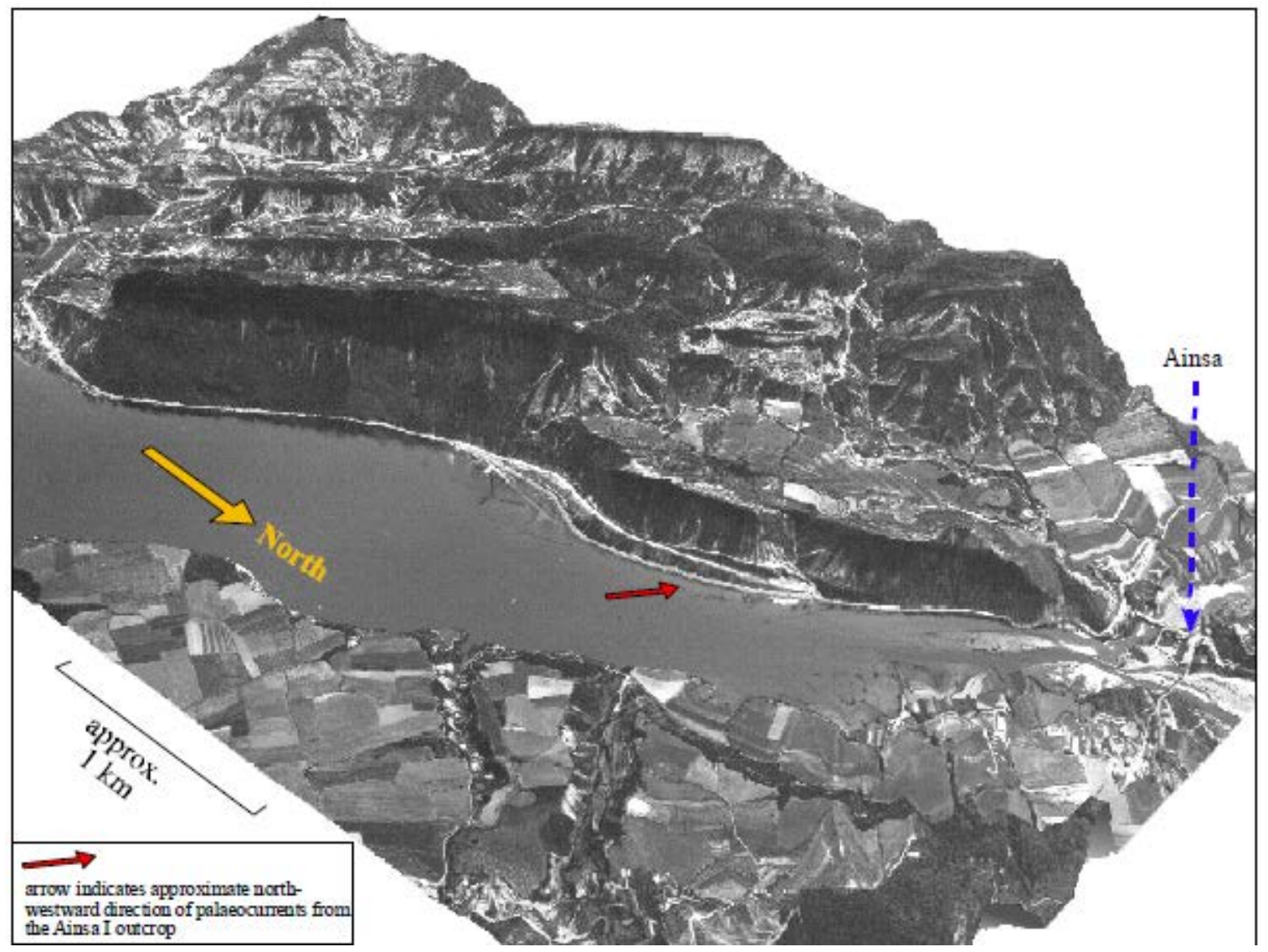

Figure 1. Example of a virtual 3D digital environment in Northern Spain which can be used for research and teaching and learning purposes.

\section{Educational egaming}

There are currently few geoscience educational egames available, perhaps due to the relatively advanced computer programming skills necessary that would be beyond most geoscience teaching and learning practitioners. In other fields, for example, forensic science, virtual crime scenes are available for learners to process so the user progress from being an initial 'rookie' at the start of the egame through to being an experienced crime scene investigator after a series of progressively more difficult virtual scenarios (see end for online link). However, the reality and difficulty of the science behind these scenarios is questionable 
and indeed how much educational value is being derived for learners is not known. An effective geoscience educational egame should deliver a realistic and science-based game that gives learners a consistent, rich and realistic experience and, ideally, the ability to replay with different pathways and/or endings and goals to encourage learner engagement.

There is an excellent online educational geoscience egame currently available, based on ore exploration, created and hosted by Leeds University (see end for online link). The learner is in charge of a virtual commercial company tasked with not only finding placer gold in a fictional digital fluvial environment, but also to generate a profit for the virtual company with significant real-world risks involved. These risks include, for example, buying secondhand equipment to cut costs which then break down, choosing the wrong exploration strategy which leads the company to financial collapse and running out of capital before the gold gets to market and can be sold to provide a revenue stream (Figure 2). At Leeds this educational egame has been embedded within the undergraduate course curriculum, and has apparently proven surprisingly effective at teaching learners about the many aspects related to ore exploration. These exploration aspects include a sensible exploration and development strategy, the need for careful financial budgeting, as well as familiarizing learners with the typical commercial development problems encountered that need to be solved to make exploration a commercial success. 


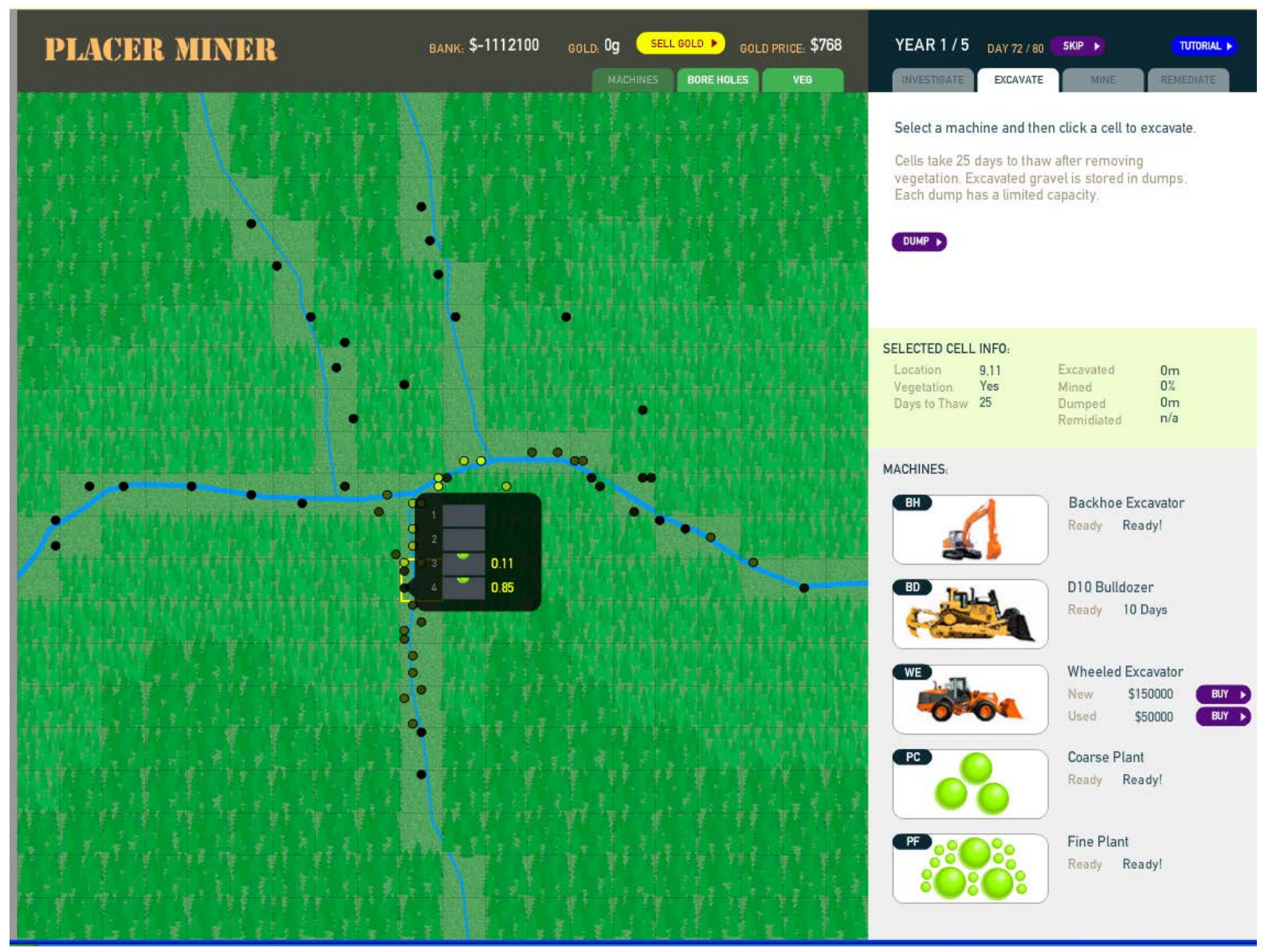

Figure 2. Digital screengrab of the exploration ore mining company educational egame, showing the virtual exploration environment, current test drill holes (black dots) and required development equipment. Courtesy of Leeds University.

\section{Environmental geotechnical placement educational egame}

At Keele University, geoscience practitioners are particularly keen on the potential for problem-based learning methods for students, which commonly bring together a variety of job-relevant skills. Comments from commercial employer contacts have mentioned that, whilst bright and having the appropriate theoretical knowledge, recent geoscience graduates struggle to correctly apply their problem-solving skills to active surveys and grasp the realities of the real- 
world by being pragmatic about time and financial constraints. This has previously been undertaken by the use of splitting learners into teams (or companies) during residential field trips to undertake phased site investigations of a set area and subsequently competitively win a 'contract'.

An educational immersive geoscience egame have been designed at Keele so the learner (user) was a Higher Education gradate level-entry employee of an environmental geotechnical company (see end for details). Based on a published site investigation case study, a virtual animated client (avatar) was asking for assistance to locate a buried coal mineshaft in the back garden of his domestic property. A multi-threaded storyline led learners through the typical site investigation stages of desk study and reconnaissance, with learners being prompted throughout to choose question/answer responses, with additional information boxes periodically embedded to further improve learning. If enough sensible questions/answers were suggested by the learner, then full geophysical survey datasets were shown which gave the opportunity to locate the mineshaft position (Figure 3), which if successful, gained a photograph of the discovered mineshaft and congratulations note. The educational egame was deliberately designed for learners to undertake multiple plays, by having different pathways (or threads) depending upon learner responses to improve the learner experience, as well as end-game humorous job titles depending upon performance to further encourage engagement. 


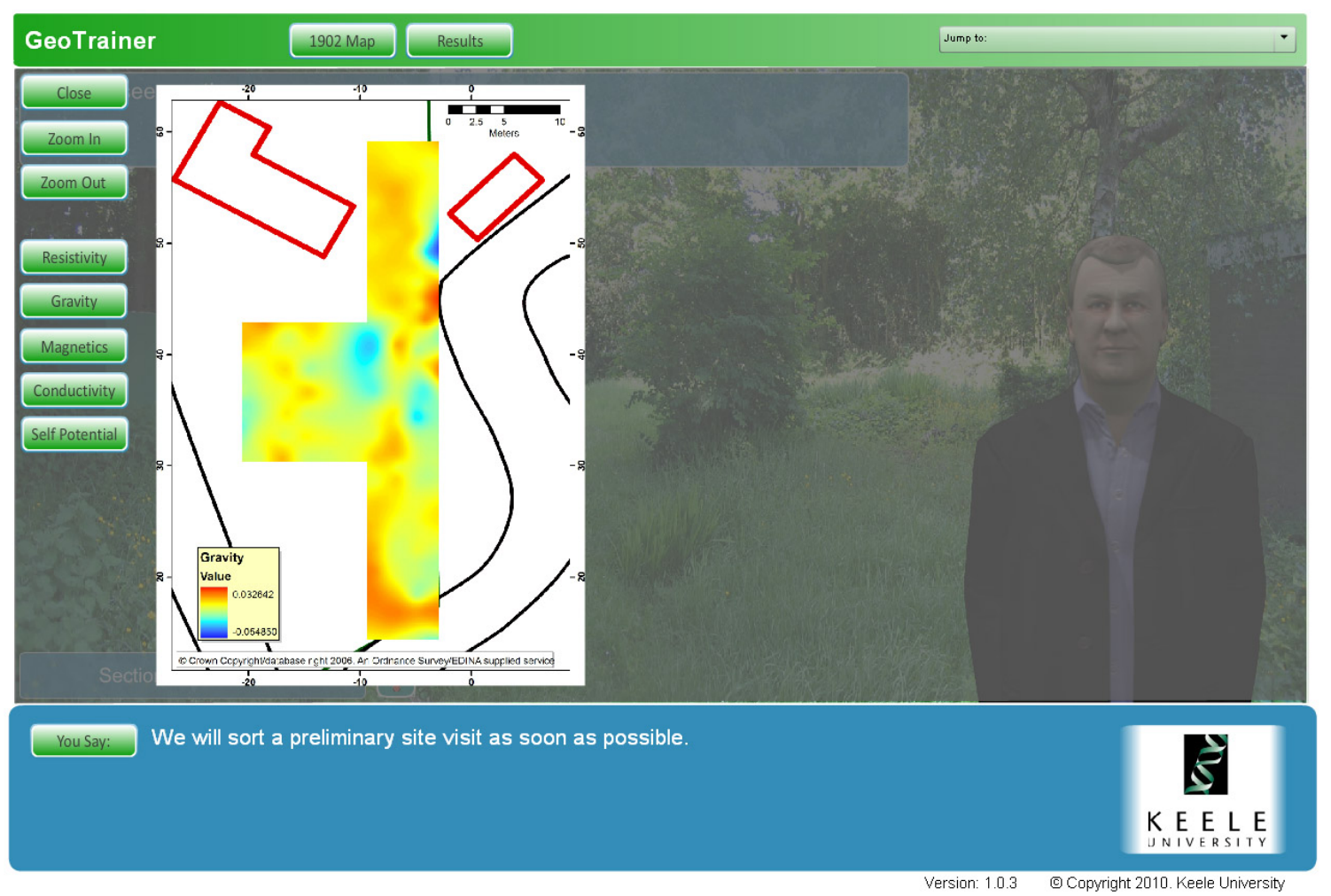

Figure 3. Digital screen grab of the environmental geotechnical egame showing the user some geophysical data collected over the survey area and requesting a suspected mineshaft position to be pinpointed (avatar client in background).

The educational e-game was trialled on 20 final year Geology student undergraduates at Keele. It was found that the participants uniformly appreciated the egame, highly rated it compared to other learning methods and thought that it was an informative learning and teaching tool. Playing the egame during a timetabled laboratory practical session also had unforeseen benefits of group learning by learners interacting and also observer assistance which further enhanced the student learning experience. Subsequent focus group learner comments suggested it was "a great fun interactive learning tool" and "useful to see how an actual job would work". Learners also mentioned that they were also more keen to read the published academic journal article on which the egame was based, which was gratifying if unexpected! 
However, the egame was restricted to the question/answer style format so it was thought beneficial to create a more advanced egame.

\section{Forensic geoscience search educational egame}

A next-generation egame was then developed by making it more immersive, to have gameplay areas that learners could freely move around in and interact with (as modern adventure, role-play and sports games types do), and to be able to virtually use survey equipment and view the results to further improve learning. This should provide a more complex learning environment in which theoretical and practical skills are learnt, decision making and learner attitudes will all play important roles.

This next-generation educational immersive egame was designed so the learner was a more experienced employee of an environmental forensic geoscience company (see end for details). Again based on a published search case study, learners work through the typical sequential steps of a forensic terrestrial search, which again involves a background case study, initial site reconnaissance and then the ability for the learner to undertake full fieldwork themselves, choosing appropriate equipment, before prioritizing suspected burial positions (Figure 4).

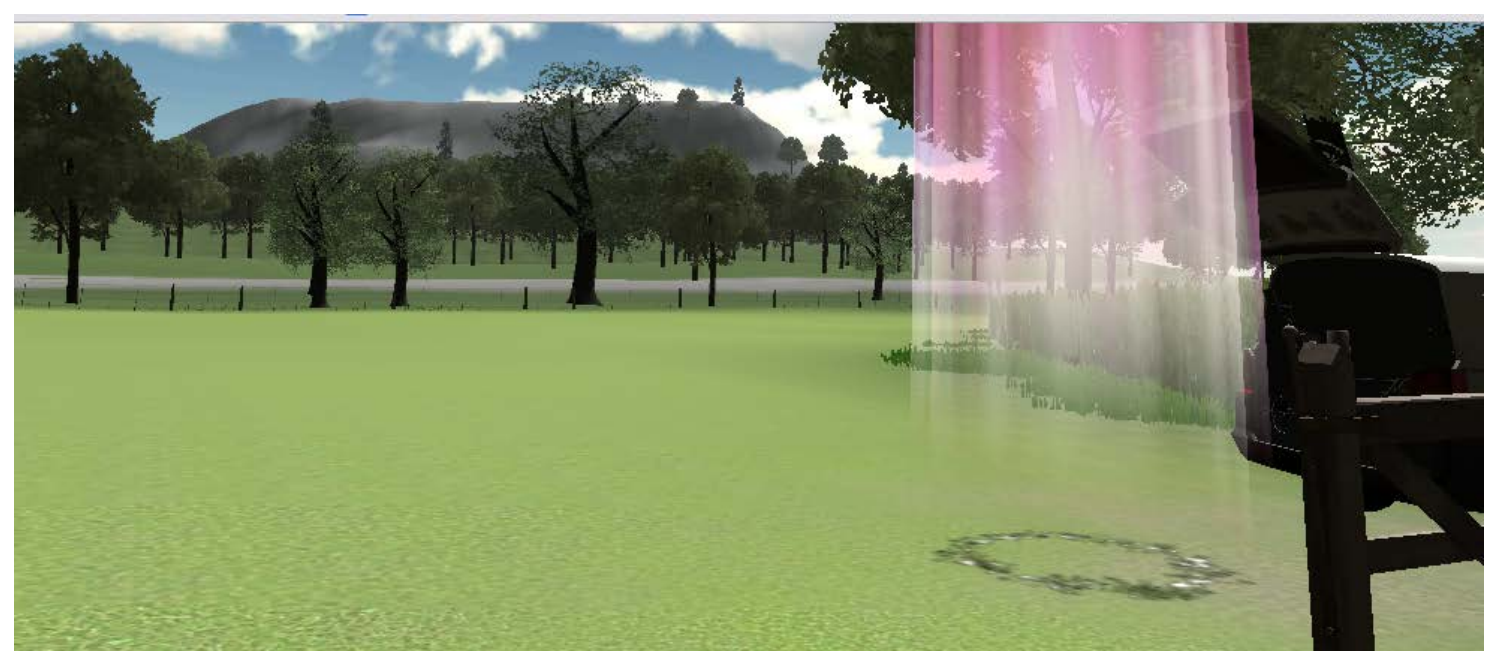


Figure 4. Digital screengrab of the environmental search educational egame showing background environment, survey van with geophysical equipment available for surveying and teleport location.

The environmental forensics education egame was again trialled on 61 Keele Geology, Geoscience and Forensic Science second and final year University undergraduates. Learners again played the egame during a timetabled laboratory practical session that showed the benefits of group learning by learners interacting. It was informative to observe a variety of gaming styles used by learners, from methodological gamers who fully explored the learning environment and completed all the steps, so-called 'lazy gamers' who simply wanted to successfully finish the egame as quickly as possible, whilst observing a few learners who did not enjoy it and generally struggled. Focus group comments evidenced the egame was again a positive experience, "useful as get chance to use all equipment in a real-life application, which can be revisited multiple times" and also wishing it to be an assessed component of a course. After analysing the assessment of the cohort after playing the egame it was found that learners had statistically improved knowledge of forensic search when compared to before playing the egame. This was suggested to evidence the educational egaming learning effectiveness of an important topic.

\section{Summary}

This paper reviews current college and HE undergradate learners who were found to indeed dominantly comprise so-called Generation $Y$, and who were found to be daily or weekly computer game users. They mostly respond positively to educational egames as effective complementary hybrid learning environments to more traditional learning and teaching methods. Educational egames provide a consistent and reliable experience which can be revisited as many times as learners require, that is not always the case with laboratory 
practicals and fieldwork. The latest immersive egames provide not only a credible alternative to outdoor fieldwork/practicals, but also allow learners 24/7 opportunities to both apply their theoretical knowledge to practical case study applications, but also gain 'experience' on certain methods/equipment that may not be physically able. Educational egames show great potential for learning and teaching at various stages of learners studies, but the egame development themselves need significant expertise, resources and time to create using present technologies. 


\section{Suggested online geoscience educational egames}

Fluvial ore placer mining game: www.see.leeds.ac.uk/misc/miner/

Environmental geotechnical placement game: www.keelesop.co.uk/geo trainer/ [contact author for username/password]

Forensic geoscience search game: www.keelesop.co.uk/csinorthwales/ [requires installation of the plug-in link]

Forensic science educational game: $\underline{\text { http://forensics.rice.edu/ }}$

\section{Suggestions for further reading}

Falloon, G. 2009. Using avatars and virtual environments in learning: what do they offer? British Journal of Educational Technology, 41, 108-122.

Pringle, J.K., Bracegirdle, L. \& Potter, J. 2014. Educational forensic e-gaming as effective learning environments for HE students. In: Williams, A., Cassella, J.P. \& A-M Muller (eds.); New Approaches in Forensic Science Education, Wiley Press.

Pringle, J.K. 2013. Educational environmental geoscience e-gaming to provide stimulating and effective learning. Higher Education Academy (GEES) Planet, 27, 21-28. 